\title{
Environmental monitoring of offshore drilling for petroleum exploration (MAPEM Project): shallow waters
}

\author{
Elírio E. Toldo Jr • Ricardo N. Ayup-Zouain • \\ Sérgio A. Netto
}

Received: 15 December 2009 / Accepted: 19 April 2010 / Published online: 2 June 2010

(C) Springer Science+Business Media B.V. 2010

\section{Introduction to the special issue}

The exploratory phase is the first step in drilling operations for oil and gas extraction in oceanic waters. If hydrocarbons are present, additional wells are then drilled to assess the dimension and outline of the petroleum accumulation. Thus, the exploratory program for the ocean areas may foresee the drilling of an expressive number of exploratory wells.

When a well is drilled, drilling fluids or mud are launched at high pressure to transport waste cuttings to the surface, maintain well stability, and to cool, lubricate, and support part of the weight of the drill bit and drill pipe (Darley and Gray 1988). Two basic types of drilling fluid are generally used, water-based fluids (WBFs) and non-aqueous fluids (NAFs). According to Darley and Gray (1988), NAFs include all fluids that are non-aqueous and non-water-dispersible, and may

E. E. Toldo Jr $(\varangle) \cdot$ R. N. Ayup-Zouain

Centro de Estudos de Geologia Costeira e

Oceânica-CECO, Universidade Federal do Rio

Grande do Sul-UFRGS, CP. 15001, 91509.900, Porto

Alegre, RS, Brazil

e-mail: toldo@ufrgs.br

\section{S. A. Netto}

Laboratório de Ciências Marinhas, Universidade do

Sul de Santa Catarina-UNISUL, Av Colombo Sales

84, 88790-000, Laguna, SC, Brazil be subdivided in three categories according to their aromatic concentration: I-high (diesel); II-medium (mineral or crude oil); III-low (paraffin or esters, known as synthetic-base fluids).

During the perforation process, drilling fluid is circulated down the drill pipe continuously and return to the rig/platform carrying drill mud and cuttings in suspension. Up in the surface, the used fluid is cleaned up by means of shale shakers, fluids cleaners, to separate the cuttings from the fluid. Fluids are then reused for drilling, while cuttings embedded with drilling fluids are discharged in the water column and deposited on the seabed. Drill cuttings range in size from clay-sized particles to coarse gravel and usually have an angular configuration (Neff et al. 2000). Depending on the depth, rate and total mass of discharge, and oceanographic conditions as well, deposited cuttings form piles of few centimeters up to $3 \mathrm{~m}$ high and spread over distances of more than $200 \mathrm{~m}$ from the outflow (Neff et al. 2000). During the exploratory phase, the deposition of cuttings and the associated fluids is the main cause of environmental changes (Breurer et al. 2004).

Extensive work has been done on the impacts of offshore oil and gas production on benthic environment at continental shelves (e.g., Olsgard and Gray 1995; Daan and Mulder 1993; Kennicutt et al. 1996; Neff et al. 2000; Breurer et al. 2004). However, most of previous studies were concentrated on longer-term impacts of production facil- 
ities at the North Atlantic and North Sea, and the drilling fluids used were mainly oil (NAF type I) and mineral oil (NAF type II).

The MAPEM project-Environmental Monitoring of Offshore Drilling for Petroleum Exploration-is the first multidisciplinary study in Southwest Atlantic to investigate the effects of cuttings discharge impregnated with one of the new-generation non-aqueous fluids (NAF type III) used for offshore drilling in deep-water and shallow environments. The results for the deepwater were recently published elsewhere (Toldo and Ayup-Zouain 2009). The present special issue presents the results obtained in shallow waters (around $200 \mathrm{~m}$ depth) at Campos basin, SE Brazil (Fig. 1).

The project was conducted with financial support by the Studies and Projects Finance Agency (Finep, Brazil), Brazilian Research Council, Brazilian Petroleum and Gas Institute, and administration by Federal University of Rio Grande do Sul Research Foundation. For the execution of the project, a multidisciplinary team was formed, composed of research groups from biology, statistics, geology, information technology, and chemistry, from Federal University of Rio Grande do Sul, Federal University of Santa Catarina, and University of Southern Santa Catarina. The program involved an intensive sampling of the study site and utilization of a variety of analytical techniques to produce a comprehensive data set. Detailed protocols and a field handbook were developed to ensure that quality assurance expectations were met as well as efficient communication among the team at onboard and laboratory activities.

\section{MAPEM sampling design}

Bottom sediments in the area surrounding wells BO-22 and BO-23, operated by the company
Fig. 1 Location of the study site at shelf break site in the Southwest Atlantic, Brazil

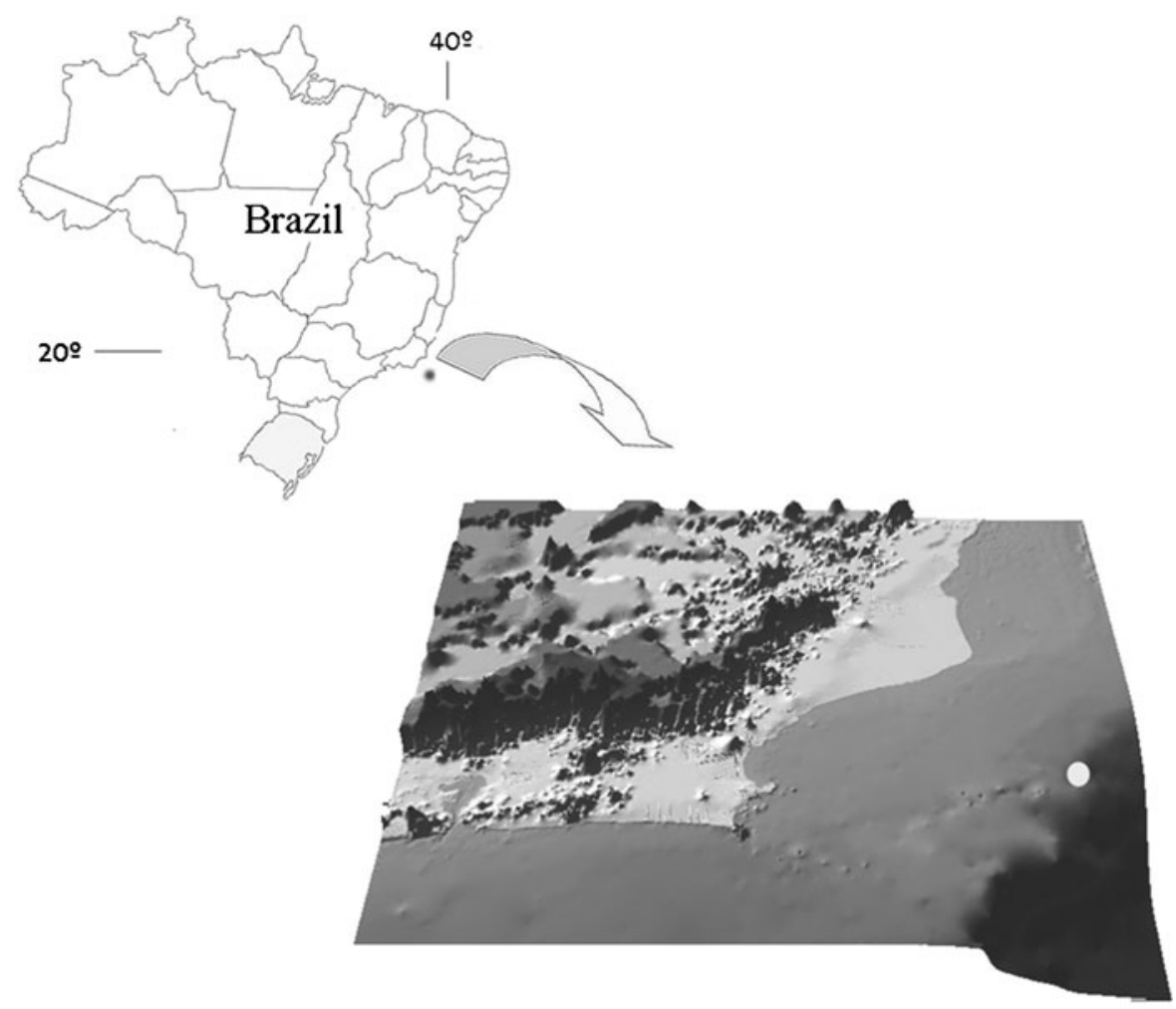

o

150 km 
PETROBRAS, originally named 7-BO-022H and 7-BO- $023 \mathrm{H}$, were collected through the use of box-corer; digital video and photography; sidescan sonar bottom images; water sampling and water column profiling, with CTD bottles; and ADCP-based current readings.

The studied area has a history of drilling activities starting in the 1970s by PETROBRAS. The last drilling activity conducted in the area occurred in 1998, at a $348 \mathrm{~m}$ distance from well BO-23, called 7-BO-019WC. In July 2001, the first oceanographic cruise for Project MAPEM took place.

The sampling design for the first oceanographic cruise was developed based on 54 sampling stations (Fig. 2), distributed as a radial concentric grid, with six sediment samples collected along circles located at 50 and $100 \mathrm{~m}$ from the site of well, and 12 others collected along circles located at 150,300 , and $500 \mathrm{~m}$ from the drilling site. Additionally, six samples were collected at a 2,500 $\mathrm{m}$ grid, referenced to the coordinates of well BO-23, to be drilled after the first oceanographic cruise (MS1). However, between the predrilling oceanographic cruise (MS1) and the first post-drilling cruise (MS2), PETROBRAS drilled a second well (BO-22), $199 \mathrm{~m}$ east of well BO23. Therefore, the same sampling grid had to be altered.

The sampling grid used for the second and third oceanographic cruises (MS2 and MS3) was structured by 74 sampling stations (Fig. 2). Out of those 74 stations, 68 were located along seven radiuses from well BO-22 up to a 500-m distance. The other six reference stations were located at 2,500 $\mathrm{m}$ from the well. Out of the total planned
Fig. 2 Dates of cruises and locations of samplings (dots) wells (left star BO-23, right BO-22) drilled between MS1 and MS3
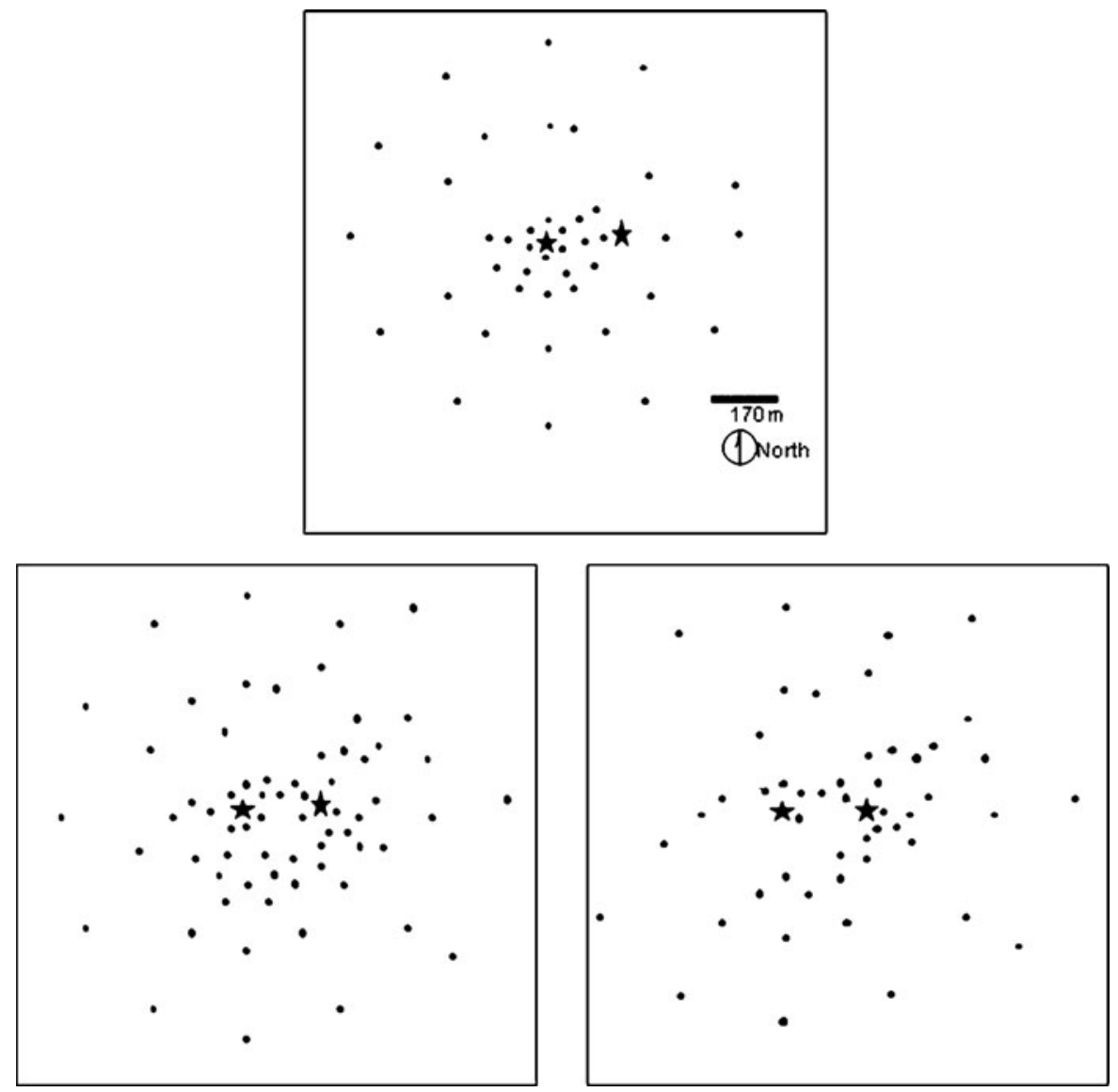
stations, 48 were sampled in MS1; 61 in MS2, 3 months after drilling; and 54 in MS3, 22 months after drilling.

The drilling activities of well BO-22 started in February 2002 and finished in April in the same year. In the location of well BO-23, the drilling activity was developed between May and June 2002.

Sampling was conducted by the ships Satro 25 and D'Diana, hired by the companies Petroleum and Environmental Geo-Services (PEG) and OceansatPeg, respectively. The three cruises were conducted on the following dates: first Cruise (MS1, pre-drilling): July 28th-31st, 2001; second Cruise (MS2, post-drilling): September 16th-24th, 2002 (14 months after the first cruise and 3 months after drilling); third Cruise (MS3, post-drilling): April 16th-19th, 2004 (19 months after the second cruise and 22 months after drilling).

\section{MAPEM results}

Six articles provide the findings and integrated synthesis of the data produced by MAPEMshallow waters. Corrêa et al. present the geological and oceanographic settings of the study site and analyzed the effects of drill cuttings discharge by sediment photograph images, sediment texture, total organic carbon, and clay mineral concentrations. No substantial changes due to drilling and cuttings discharge were detected in sediments properties. Photographs taken from the box-corers revealed the presence of dark spots, predominantly in MS2, in the area surrounding wells BO-22 and BO-23. Such spots probably result from effects of cuttings from the NAF drilling phase.

In the second article, Pivel and Freitas provide data on discharge modeling performed by the Mud Discharge Model, by OOC-Offshore Operators Committee. The OOC Model simulates the discharges from the two drilled wells at Campos Basin, and compared the results with field observations obtained 3 months after drilling. The comparison showed that the model provided reasonable predictions, considering that data about currents were reconstructed and theoretical data were used to characterize the classes of solids. The model proved to be a valuable tool to determine the degree of potential impact associated to drilling activities. However, since the accuracy of the model is directly dependent on the quality of input data, different possible scenarios should be considered when used for forecast modeling.

Peralba et al. deal with the impact of drilling cutting discharge on metals (Al, Fe, Mn, Ba, Co, $\mathrm{Pb}, \mathrm{Cu}, \mathrm{As}, \mathrm{Hg}, \mathrm{Cr}, \mathrm{Ni}, \mathrm{Zn}, \mathrm{Cd}$, and $\mathrm{V}$ ) and aliphatic and polynuclear aromatic hydrocarbons concentrations in the sediment. No significant variation was observed for the metals after drilling activities, with the exception of Ba. Hydrocarbon contents suggest previous anthropogenic activities in the region. Aliphatic hydrocarbon contents were in the range usually reported in other drilling sites. The same behavior was observed in the case of polyaromatic hydrocarbons. Nevertheless, the $n$-alkanes concentration increased up to 22 nd month after drilling activities, decreasing thereafter.

Data on macrofauna and meiofauna responses to drill cuttings discharge are provide by Santos et al. and Netto et al., respectively. The effects of drilling activities on the macrobenthic communities were the result of the deposition of drill cuttings, and the anoxic conditions established in the substrate, which characterized both physical and chemical impacts. The effects were restricted to an area subjected to $\mathrm{WBF} / \mathrm{NAF}$. At the impacted area, low diversity values were found 3 months after drilling, with a dominance of opportunistic organisms such as Capitellidae (genus Capitella). Twenty-two months after drilling, an ecological succession process was evident, with an increase of diversity, changes in fauna composition, and a dominance of opportunistic deep-burrowing and tube-building organisms. Yet the effects on meiofauna communities were dependent on the fluid used (if water-based or synthetic/water-based drilling fluid) and the background state (if it already presented signs of previous drilling activities or not). The results of meiofauna data evidence that the most affected area after drilling was those under the influence of NAF and that already had signs of previous drillings activities. The region impacted by WBF was less affected and completely recovered after 22 months. Nematodes and 
copepods had different responses to the impact. While copepods flourish in the impacted area and recovered 22 months after drilling, nematodes were adversely affected shortly after drilling and the community structure only recovered where hydrocarbons had been depleted.

The last article, by Pulgati et al., describes the use of Bayesian spatial models to develop the concept of a spatial-temporal mask with the aim of identifying areas in which before and after-drilling effects are most clearly defined. The method uses the BACI (Before-After ControlImpact) approach. Barium and light hydrocarbons were used as chemical tracers for water-based and non-aqueous-based fluids. Since the site showed evidence of exposure to waste material from earlier drillings, the analysis needed to take into account the background concentrations of these compounds. Using the Bayesian models, concentrations at unsampled sites were predicted and areas affected and previously contaminated were identified.

Acknowledgements This project has been supported by Financiadora de Estudos e Projetos-FINEP, under contract 64.00.0466, Instituto Brasileiro do Petróleo e GásIBP, and fellowships from Conselho Nacional de Desenvolvimento Científico e Tecnológico-CNPq. We thank Luiz Molle, Cristiano Pamphili, Leticia Veiga, Anna Scofano, Álvaro Cintra, Rodger Melton, Raul Mosman, Jonas Fonseca, from IBP, for their cooperation and facilities to the development of the oceanographic cruises. We thank Julio Wasserman for the substantial data analysis, Emil
Olafsson for helpful comments and all consultants of the MAPEM Project are thanked for their contributions.

\section{References}

Breurer, E., Stevenson, A. G., Howe, J. A., Carroll, J., \& Shimmield, G. B. (2004). Drill cutting accumulations in the Northern and Central North Sea: A review of environmental interactions and chemical fate. Marine Pollution Bulletin, 48, 12-25.

Daan, R., \& Mulder, M. (1993). Long term effects of OBM cutting discharges at a drilling site on the Dutch Continental Shelf. Netherlands Institute for Sea Research (NIOZ) internal report 1993-15.

Darley, H. C. H., \& Gray, G. G. (1988). Composition and properties of drilling and completion fluids. Houston: Gulf Publishing Co.

Kennicutt II, M. C., Green, R. H., Montagna, P. A., \& Roscigno, P. F. (1996). Gulf of Mexico offshore operations monitoring experiment-GOOMEX, Phase I: Sublethal responses to contaminant exposureIntroduction and overview. Canadian Journal of Fishery and Aquatic Science, 53, 2540-2533.

Neff, J. M., McKelvie, S., \& Ayers, R. C. (2000). Environmental impact of synthetic based drilling fluids. New Orleans: U.S. Department of Interior, Minerals Management Service.

Olsgard, F., \& Gray, J. S. (1995). A comprehensive analysis of the effects of offshore oil and gas exploration and production on the benthic communities of the Norwegian continental shelf. Marine Ecology Progress Series, 122, 277-306.

Toldo Jr, E. E., \& Ayup-Zouain, R. N. (2009). Environmental monitoring of offshore drilling for petroleum exploration (MAPEM): A brief overview. Deep Sea Research II, 56, 1-3. 